\title{
Electrical grid reliability assessment by fault tree analysis
}

\author{
A. M. Agwa1 ${ }^{1}$ H. M. Hassan' ${ }^{2}$ Z. E. Matter ${ }^{3}$, E. A. Eisawy ${ }^{4}$ \\ ${ }^{1,3}$ Faculty of Engineering, Al-Azhar University, Egypt \\ ${ }^{2,4}{ }^{2}$ ggyptian Nuclear and Radiological Regulatory Authority, Egypt
}

\begin{tabular}{l}
\hline \hline Article Info \\
\hline Article history: \\
Received Apr 6, 2019 \\
Revised Jul 8, 2019 \\
Accepted Sep 26, 2019 \\
\hline
\end{tabular}

Keywords:

Ac load flow

Electrical grid

Fault tree

Reliability

\begin{abstract}
The main rule of an electrical grid is to supply electrical energy to consumers as economically as possible, and with an adequate degree of reliability. Reliability is an essential measure and important component of all power system planning and operation procedures. In this paper, the electrical grid reliability is evaluated by Fault Tree (FT) analysis. In this method Alternating Current (AC) load flow analysis is combined with the FT technique. The electrical grid reliability is calculated based on the unreliability of the power supplied to the loads. The verification of the method is performed on a part of the Egyptian electrical grid (Alexandria zone 17-bus). The electrical grid components are sorted according to their influence on the electrical grid reliability.
\end{abstract}

Copyright $\odot 2020$ Institute of Advanced Engineering and Science. All rights reserved.

\section{Corresponding Author:}

H. M. Hassan,

Egyptian Nuclear and Radiological Regulatory Authority,

Ahmed El-Zomor St., Nasr City, Cairo, Egypt.

Email: eng.hamdy99@gmail.com

\section{INTRODUCTION}

The basic function of an electrical grid is to fulfill the system load demands as efficiently as possible and with an acceptable assurance of reliability. Reliability is one of the fundamental design aspects when designing critical, complex and costly systems. In order to reach the needed degree of reliability, electrical grid planners, managers, designers and operators have applied a wide range of criteria in their corresponding areas of activity. The evaluation of the overall electrical grid reliability is very complicated as it is necessary to include detailed modeling of both generation and transmission facilities and their support systems. A failure of components or subsystems can cause a failure of power supplied to certain loads or in some cases in a full blackout of the electrical grid [1,2].

Most of the electrical grid reliability assessment approaches use approximation orsimplification of the problem to degrade the problem at a solvable level. The most economical and reliable expansion alternative of a power system to meet the expected future load growth using a heuristic algorithm is selected in [3]. In [4] a real-time design of efficient monitoring and control of grid power system is presented using the remote cloud server to fetch, monitor and control the real-time power system data to improve the universal control and response time. In [5] a supervisory controller model is used to regulate a hybrid energy system consisting of photovoltaic, solid oxide fuel cell, electrolyzer system and a storage tank according to load requirement. A software defined networking to change notion of traditional networks by decoupling control and forwarding planes is introduced in [6]. A Volkanovski et al. presented a statistical analysis of the Lose of Offsite Power (LOOP) registered in four assessed databases, the number of LOOP events in each year in the period studied and operation modes are assessed [7,8]. A case study of the power station is considered for performing the FT analysis and the results are presented in [9]. The methodology adopted in the investigation is to generate FT for each load point of the power system. In [10] FT technique based on generalized fuzzy numbers to a distribution possibility of reliability indices for power systems is illustrated. All the failure probabilities are characterized by generalized trapezoidal fuzzy number. A real case study for 
the US Surry Nuclear Power Plant (NPP) which was touched down by a tornado in 2011 causing the electrical switchyard damage and LOOP is executed in [11]. A method for assessing LOOP Initiating Event (IE) probability are reviewed and improved. The probability is evaluated and the current plant performance and power system are matched to the plant performance and power system performance from years ago. In [12] M. S. Javadi presented surveys on the FT Analysis in modelling the reliability assessment of an engineering system using Boolean algebra. This approach can be implemented for calculation the reliability indices, regardless of the complexity of the modelling of large scale system.

The objective of this paper is to evaluate the electrical grid reliability using FT analysis technique. The method combines AC load flow method with the FT analysis features. The verification of the method is performed on a part of the Egyptian grid (Alexandria zone 17 bus). FT analysis is performed using SAPHIRE-8 software. The electrical grid components are sorted according to their influence on the electrical grid reliability.

\section{ELECTRICAL GRID RELIABILITY ANALYSIS}

In order to estimate the electrical grid reliability, it is necessary to develop a method for estimation of the load supplying capability of the electrical grid to each load point of the system. FT analysis approach was selected for estimation of reliability indices of the power supplied to each load in the system. The corresponding FT is built for each load in the system. The unreliability of the power supplied to each load is estimated through the top event probability of the respective FT, and the weighted unreliabilities of power supplied to all loads are considered to get the whole measure of the electrical grid reliability [13].

The electrical grid reliability can be defined from its complement, i.e., unreliability as follows [14]:

$$
\begin{aligned}
& R_{P S}=1-U_{P S} \\
& U_{P S}=\sum_{i=1}^{N} U_{i} \frac{K_{i}}{k}
\end{aligned}
$$

where:

$\mathrm{R}_{\mathrm{PS}}$ : the electrical grid reliability.

$\mathrm{U}_{\mathrm{PS}}$ : the electrical grid unreliability.

$\mathrm{U}_{\mathrm{i}}$ : the unreliability of the power supplied to the load $\mathrm{i}$.

$\mathrm{N}$ : the number of loads in a system.

$\mathrm{K}_{\mathrm{i}}$ the size of load $\mathrm{i}(\mathrm{MW})$.

$\mathrm{K}$ : the complete load of the electrical grid represented as the sum of all the loads.

$\mathrm{K}_{\mathrm{i}} / \mathrm{K}$ : the weighting factor for load $\mathrm{i}$.

The electrical grid unreliability for each load $\left(\mathrm{U}_{\mathrm{i}}\right)$ can be calculated as the top event probability of the corresponding FT analysis.

\section{FAULT TREE ANALYSIS}

The FT analysis is a standard method for the assessment and improvement of reliability and safety [15-17]. The FT analysis is defined as: "an analytical technique, where an undesired state of the system is specified and then the system is analyzed in the context of its environment and operation to find all realistic ways in which the undesired event can occur". The undesired state of the system, which is identified at the beginning of the FT analysis, is normally a state that is critical from a safety or reliability point of view and is identified as the top event. Consequently, a top event is, therefore, an undesired event, which is further investigated with the FT analysis [18].

The logical gates of the FT incorporate the primary events to the top event. The primary events are the events that are not further developed, e.g., the basic events (BEs) and the house events. The BEs are the ultimate parts of the FT, which represent the undesired events and their failure modes, e.g., the component failures, the lost actuation signals, the human errors, the unavailabilities due to test and maintenance activities, the common cause failure (CCF) contributions and software errors. CCF events are a group of dependent events where at the same time there are two or more components exist at failure condition as a result of a shared root cause. An example is a case where two parallel power transmission lines connected to the same tower, or two transmission lines share the same right of way [19-21].

FT is represented mathematically by a set of Boolean equations. The qualitative analysis (in the process of Boolean reduction of a set of equations) identifies the minimal cut sets (MCSs). MCSs are combinations of the smallest number of BE that lead to the top event if occur simultaneously. 
In general, the equations for representing the MCSs as the result of the qualitative FT analysis are joined into the following equation [14].

$$
P_{M C S i}=\prod_{j=1}^{J} B_{j}
$$

where:

$\mathrm{P}_{\mathrm{MCSi}}$ : the probability of occurrence of MCS $\mathrm{i}$

$B_{j}:$ the $B E j$.

$\mathrm{J}$ : number of BEs in a particular MCS.

The quantitative FT analysis represents a calculation of the top event probability, equal to the failure probability of power supplied to the respective load. The calculation of the top event probability (using rare event approximation) as [14]:

$$
P_{T O P}=U_{i}=\sum_{i=1}^{I} P_{M C S_{i}}
$$

where:

PTOP: the top event probability of the FT.

I: number of MCSs.

Electrical components can be sorted according to their influence on the electrical grid reliability. In general, the importance of a component within a system depends on the position of the component in the system, on the reliability of the component, and the reliability of the system. Two importance measures are introduced. The first one is the Network Risk Achievement Worth (NRAW) this importance measure shows the increase in the probability of the FT top event that would be obtained if the failure of a component is occurred. The second one is the Network Risk Reduction Worth (NRRW) this importance measure shows the decrease in the probability of the FT top event that would be obtained if the failure of a component did not occur. NRAW and NRRW can be defined as follows [14]:

$$
\begin{aligned}
& N R A W_{i}=\frac{U_{P S}\left(U_{i}=1\right)}{U_{P S}} \\
& N R R W_{i}=\frac{U_{P S}}{U_{P S}\left(U_{i}=0\right)}
\end{aligned}
$$

where:

NRAW $_{\mathrm{k}}$ : the network risk achievement worth of the component $\mathrm{k}$.

$\mathrm{NRRW}_{\mathrm{k}}$ : the network risk reduction worth of the component $\mathrm{k}$.

$\mathrm{U}_{\mathrm{PS}}\left(\mathrm{U}_{\mathrm{k}}=1\right)$ : the unreliability of the electrical grid when unreliability of the component k is set to 1 .

$\mathrm{U}_{\mathrm{PS}}\left(\mathrm{U}_{\mathrm{k}}=0\right)$ : the unreliability of the electrical grid when unreliability of the component $\mathrm{k}$ is set to 0 .

\section{FAULT TREE CONSTRUCTION}

The first step in construction of the corresponding FT is identification of all the possible energy flow paths from the adjacency matrix of the corresponding power system. The five buses system shown on Figure 1, is presented as an example for the description of the method.

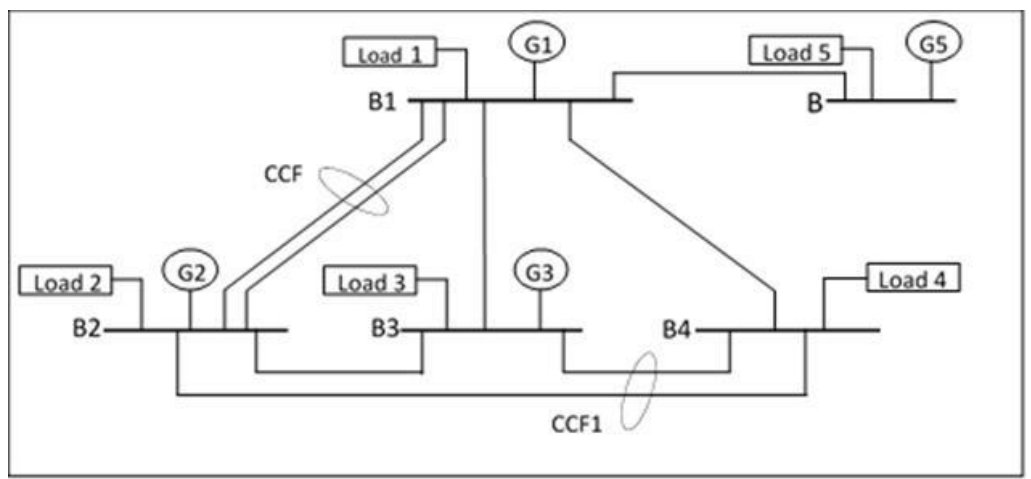

Figure 1. Example power system with 5 buses 
The system consists of five buses, four generators in buses 1, 2, 3 and 5 and loads in all buses. There are multiple lines (marked L12 and L12') between buses 1 and 2 in the example system. The lines for which CCF are accounted are marked on Figure 1. The CCF of lines between buses 1 and 2 is due to the common tower. The CCF1 of the line between buses 4 and 3 and part of the line between buses 4 and 2 is due to common right-of-way for part of their length [22].

The representation of the system topology is performed through the adjacency matrix A. The adjacency matrix is a matrix with the rows and columns labeled with a 1 or 0 in position (Aij) according to whether the bus $\mathrm{i}$ is connected to bus $\mathrm{j}$ directly or not. The rows follow the running index $\mathrm{i}$ of buses. The columns follow the running index $\mathrm{j}$ of buses. If the value of position Aij is 0 , the buses $\mathrm{i}$ and $\mathrm{j}$ are not directly connected. If the value of position Aij is 1 , the buses $\mathrm{i}$ and $\mathrm{j}$ are directly connected. The diagonal elements of the matrix equal 0 , as the bus is not connected to itself. The adjacency matrix $\mathrm{A}$ of an example system is given on Figure 2 [23].

$$
A=\left[\begin{array}{lllll}
0 & 1 & 1 & 1 & 1 \\
1 & 0 & 1 & 1 & 0 \\
1 & 1 & 0 & 1 & 0 \\
1 & 1 & 1 & 0 & 0 \\
1 & 0 & 0 & 0 & 0
\end{array}\right]
$$

Figure 2. Adjacency matrix A of an example system

The next step is the identification of power flow paths between the load and other buses in system using the rooted tree. A rooted tree is a tree in which a labeled node is singled out. The rooted tree for load 1 is given on Figure 3 (a).

The identified flow paths of energy delivered between buses are tested for consistency as follows:

a) If there is overloaded line in the flow path, then that flow path is rejected.

b) If there is bus with a violated voltage in the flow path, then that flow path is rejected.

Test of overloaded lines in a flow path and voltages in the buses is performed using AC load flow model, using load flow method all active and passive power flow in the lines and voltage magnitude and angle for each bus in the system are defined. In case of line overloaded above the thermal limits or any voltage magnitude exceed the limits (i.e. $\pm 5 \%$ of rated value), then this branch or bus in not accepted in the FT construction [24].



(a) Without consistency test

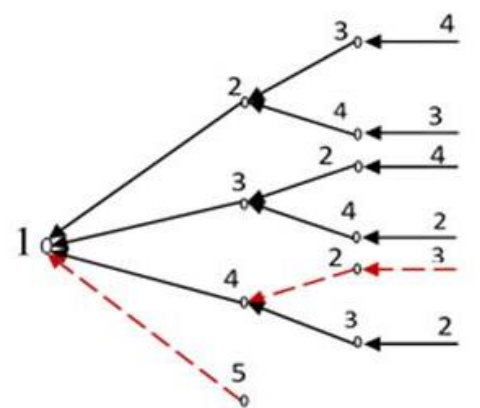

(b) After applying consistency test

Figure 3. (a) and (b): The rooted tree for load 1

For the example power system, let the line between bus 2 and 4 is overloaded for specific flow path corresponding to the power delivered from bus 2 to bus 4 . Also, let the voltage in bus 5 is lower than nominal due to the limited capacity of generator 5 . In that case, only flow paths marked with the dark solid lines are accepted for FT construction. The overloaded line and violated voltage which marked with dashed lines are shown in Figure 3 (b). Flow paths accepted in previous test of consistency, are used in next step for the FT construction. The FT constructed for the load 1 of the example system, is created using the modular FT as shown in Figure 4. 




Figure 4. The fault tree built for load 1

\section{CASE STUDY RESULTS}

The verification of the method is performed on the Egyptian Grid (Alexandria zone) 17-bus, the system consisting of 17 buses (12 buses directly connected to loads and 5 buses directly connected to generators), 18 generators and 35 power lines. For 16 lines, CCF are considered. The bus data, line data, generation data and component failure rates can be found in [14, 25]. Single line diagram of the Alexandria zone 17-bus is given in Figure 5.

FT analysis is done using Systems Analysis Programs for Hands-on Integrated Reliability Evaluations (SAPHIRE-8) software. SAPHIRE-8 is an integrated Probabilistic Safety Assessment software tool that gives a user the ability to create and analyze FTs using a personal computer. SAPHIRE-8 development and maintenance has been carried out by the Idaho National Laboratory.

Table 1 shows the calculated unreliability for all load buses (17 buses) in Alexandria Zone together with their weighted unreliability. The first and second columns in Table 1 identifies buses numbers and names where the loads are connected. The third column gives the unreliability of the power supplied to the 
respective load. The fourth column shows the load size in the buses. The fifth column gives the weighting factor equal to the load for the respective bus divided by the total load. The sixth column gives the product of the unreliability and the weighting factor. The last two rows show the total weighted system unreliability and the total system reliability.

As shown in Table 1 the highest buses unreliabilities are buses 5, 8 and 17 due to fewer connections between the other buses in the system. Also, the lowest buses unreliabilities are buses 2, 4 and 15 due to the more connections between the other buses in the system and/or generating units connected to these buses. The NRAW and NRRW for selected elements of the electrical grid are given in Tables 2 and 3 respectively.

Table 2 shows the largest NRAW components, generator in bus 15, CCF for the double lines between buses $2-6$, the line between buses $6-8$ and generators in buses 4 and 16 have the largest NRAW values. These five components have the highest influence on the decrease in the electrical grid reliability if they fail.

Table 3 shows the largest NRRW components, buses No. 2, 15 and 14, generator in bus 16 and line between buses $6-8$ have the largest NRRW values. These five components have the highest influence on the increase in the electrical grid reliability if they did not fail.

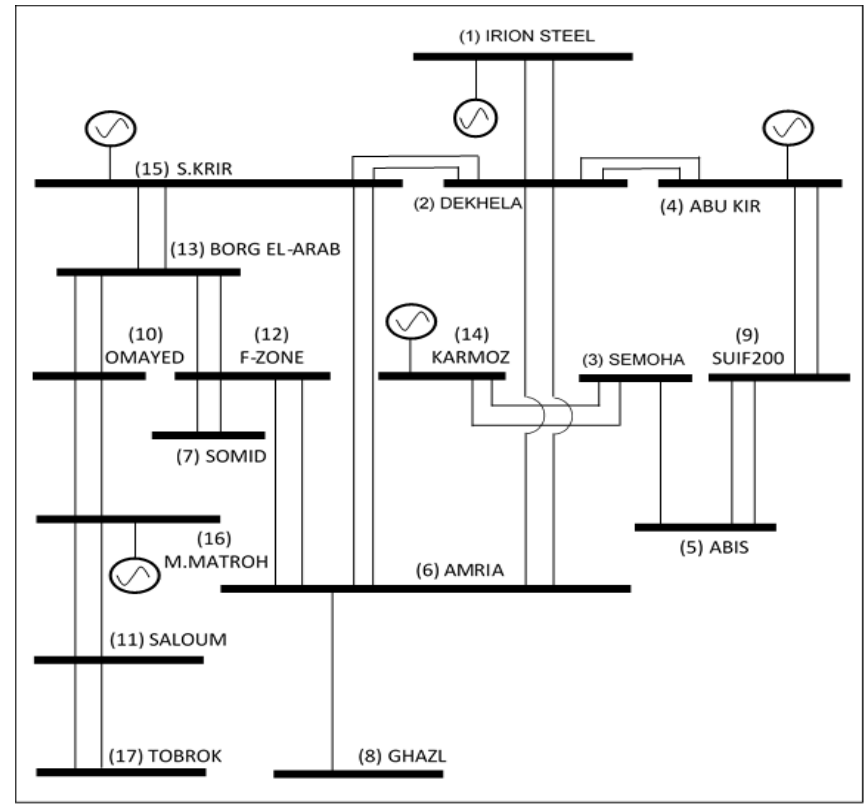

Figure 5. Alexandria Zone 17-bus single line diagram

Table 1. Calculated Unreliability for All Load Buses in Alexandria Zone 17-bus Power System

\begin{tabular}{cccccc}
\hline Bus No. & Bus Name & $\begin{array}{c}\text { The unreliability of the } \\
\text { power supplied to the load }\end{array}$ & Pload (MW) & $\begin{array}{c}\text { weighting factor } \\
\text { Weighted unreliability of the } \\
\text { power supplied }\end{array}$ \\
\hline 1 & IRON STE & $5.46 \mathrm{E}-04$ & 343.538 & $1.83 \mathrm{E}-01$ & $9.98 \mathrm{E}-05$ \\
2 & DEKHELA & $4.43 \mathrm{E}-05$ & 128.958 & $6.86 \mathrm{E}-02$ & $3.04 \mathrm{E}-06$ \\
3 & SEMOHA & $4.74 \mathrm{E}-05$ & 272.588 & $1.45 \mathrm{E}-01$ & $6.87 \mathrm{E}-06$ \\
4 & ABU KIR & $4.43 \mathrm{E}-05$ & 101.051 & $5.38 \mathrm{E}-02$ & $2.38 \mathrm{E}-06$ \\
5 & ABIS & $7.50 \mathrm{E}-02$ & 121.259 & $6.45 \mathrm{E}-02$ & $4.84 \mathrm{E}-03$ \\
6 & AMRIA & $8.50 \mathrm{E}-05$ & 116.207 & $6.18 \mathrm{E}-02$ & $5.25 \mathrm{E}-06$ \\
7 & SOMID & $5.49 \mathrm{E}-04$ & 25.371 & $1.35 \mathrm{E}-02$ & $7.41 \mathrm{E}-06$ \\
8 & GHAZL & $6.00 \mathrm{E}-02$ & 55.31 & $2.94 \mathrm{E}-02$ & $1.77 \mathrm{E}-03$ \\
9 & SUIF200 & $5.46 \mathrm{E}-04$ & 241.113 & $1.28 \mathrm{E}-01$ & $7.01 \mathrm{E}-05$ \\
10 & OMAYED & $2.05 \mathrm{E}-02$ & 29.928 & $1.59 \mathrm{E}-02$ & $3.27 \mathrm{E}-04$ \\
11 & SALOUM & $2.05 \mathrm{E}-02$ & 9.143 & $3.27 \mathrm{E}-03$ & $6.71 \mathrm{E}-05$ \\
12 & F ZONE & $5.49 \mathrm{E}-04$ & 176.255 & $9.16 \mathrm{E}-02$ & $2.83 \mathrm{E}-05$ \\
13 & BORG EL-ARAB & $8.06 \mathrm{E}-03$ & 126.311 & $6.72 \mathrm{E}-02$ & $7.56 \mathrm{E}-04$ \\
14 & KARMOZ & $5.44 \mathrm{E}-04$ & 5 & $2.66 \mathrm{E}-03$ & $3.66 \mathrm{E}-05$ \\
15 & S.KRIR & $1.69 \mathrm{E}-03$ & 27.655 & $1.47 \mathrm{E}-02$ & $4.50 \mathrm{E}-06$ \\
16 & M.MATROH & $2.00 \mathrm{E}-03$ & 6 & $3.19 \mathrm{E}-03$ & $2.94 \mathrm{E}-05$ \\
17 & TOBROK & $5.05 \mathrm{E}-02$ & & & $1.61 \mathrm{E}-04$ \\
Weighted system & & & $4.83 \mathrm{E}-04$ \\
System reliability & & & & 0.999517 \\
\hline
\end{tabular}


Table 2. Components with the Largest NRAW

\begin{tabular}{ccc}
\hline Component & NRAW & Description \\
\hline GEN_15 & $2.06 \mathrm{E}+01$ & Generator 15 failure \\
CCF_2_6 & $1.96 \mathrm{E}+01$ & CCF between lines 2-6 \\
LINE_6_8 & $1.81 \mathrm{E}+01$ & Line 6-8 failure \\
GEN_4 & $1.81 \mathrm{E}+01$ & Generator 4 failure \\
GEN_16 & $1.78 \mathrm{E}+01$ & Generator 16 failure \\
\hline
\end{tabular}

Table 3. Components with the Largest NRRW

\begin{tabular}{ccc}
\hline Component & NRAW & Description \\
\hline BUS_2 & $1.13 \mathrm{E}+05$ & Bus 2 failure \\
BUS_15 & $3.16 \mathrm{E}+01$ & Bus 15 failure \\
BUS_14 & $3.02 \mathrm{E}+00$ & Bus 14 failure \\
GEN_16 & $1.49 \mathrm{E}+00$ & Generator 16 failure \\
LINE_6_8 & $1.02 \mathrm{E}+00$ & Line 6-8 failure \\
\hline
\end{tabular}

\section{CONCLUSION}

FT technique and AC load flow analysis were utilized to assess the electrical grid reliability based on the unreliability of the power supplied to the loads in the electrical grid. The results depend on the components failure probabilities, load flow and topology of the electrical grid. The obtained results help in concentrating the attention on those parts of the electrical grid that participate largely to the unreliability of the electrical grid. The method was applied on the Egyptian electrical grid (Alexandria Zone 17-bus). Electrical grid components were sorted according to their influence on the electrical grid reliability, and the most important components were defined. The proposed method is efficient in assessing electrical grid reliability and selecting the components which have an influence in the electrical grid reliability.

\section{REFERENCES}

[1] L. Nyman and S. Rantala. "Development of a probabilistic risk analysis example using a computer tool for dynamic event tree modeling", 2016.

[2] Z. Li, "Loss of Offsite Power Frequency Calculation II", Probabilistic Safety Assessment and Management PSAM 12, June 2014.

[3] A. S. Dalabeeh, et al., "Economical and Reliable Expansion Alternative of Composite System under Restructuring", International Journal of Electrical and Computer Engineering (IJECE) 8, No. 6, pp. 4790-4799, 2018.

[4] N. Kulkarni, and S. A. Deokar, "Real time control and monitoring of grid power systems using cloud computing" International Journal of Electrical and Computer Engineering (IJECE) 9, No. 2 (2019): 941

[5] S. K. Bhuyan, P. K. Hota, and B. Panda, "Modeling and simulation of grid connected hybrid energy system and its fault analysis" International Journal of Power Electronics and Drive Systems (IJPEDS) 9, No. 2 (2018): 775

[6] T. E. Ali, A. H. Morad, M. A. Abdala, "Load Balance in data center SDN Nerworks", International Journal of Electrical and Computer Engineering (IJECE) 8, No. 5, pp. 3086-3092, 2018.

[7] A. Volkanovski, et al., "Statistical Analysis of Loss of Offsite Power Events", Science and Technology of Nuclear Installations, 2016.

[8] A. Volkanovski, et al., "Summary Report on Events Related to Loss of Offsite Power and Station Blackout at NPPs", JRC technical report, 2016.

[9] J. Jaise, et al., "Power system: a reliability assessment using FTA", International Journal of System Assurance Engineering and Management 4.1, pages: 78-85, 2013.

[10] M. Verma, et al., "Power system reliability evaluation using fault tree approach based on generalized fuzzy number", Journal of Fuzzy Set Valued Analysis, 2012.

[11] M. Borysiewicz, et al., "Loss of offsite power caused by tornado in Surry NPP - a case study", Journal of Polish Safety and Reliability Association Summer Safety and Reliability Seminars, Volume 6, Number 3, 2015.

[12] M. S. Javadi, et al., "Fault tree analysis approach in reliability assessment of power system", International Journal of Multidisciplinary Sciences and Engineering 2.6, (2011): 46-50

[13] A. Volkanovski, "Impact of offsite power system reliability on nuclear power plant safety", $\mathrm{PhD}$ thesis, University of Ljubljana, 2008.

[14] A. Volkanovski, et al., "Application of the fault tree analysis for assessment of power system reliability", Reliability Engineering \& System Safety 94.6, 2009.

[15] D. A. Nelson, "Introduction to fault tree analysis", Annual Reliability and Maintainability Symposium. USA, 2018.

[16] H. Fazlollahtabar, and S. T. Niaki, "Fault Tree Analysis for Reliability Evaluation of an Advanced Complex Manufacturing System." Journal of Advanced Manufacturing Systems17.01, pp. 107-118, 2018.

[17] J. Katoen and M. Volk, "A Modern Perspective on Fault Tree Analysis", RWTHAACHEN university, Byline, 2018. 
[18] D. Ge, Shanqi, at al., "Dynamic Fault Tree Analysis for NPP Emergency Diesel Generator System”, Transactions of the American Nuclear Society, Vol. 118, Philadelphia, Pennsylvania, June 17-21, 2018.

[19] M. Cepin, "Development of new method for assessing reliability of a network", Proceeding of PSAM8, New Orleans, USA, 2006.

[20] D. Kančev, et al., "Application of probabilistic safety assessment for macedonian electric power system", International Conference Nuclear Energy for New Europe, Portorož, 2007.

[21] C. L. Smith and S. T. Wood, "Systems Analysis Programs for Hands-on Integrated Reliability Evaluations (SAPHIRE): Version 8", US Nuclear Regulatory Commission, Office of Nuclear Regulatory Research, 2011.

[22] A. Bhandakkar, "Real-Time-Simulation of IEEE-5-Bus Network on OPAL-RT-OP4510 Simulator." IOP Conference Series: Materials Science and Engineering. Vol. 331. No. 1. IOP Publishing, 2018.

[23] R. D. Zimmerman and C. E. Murillo-Sanchez, "Matpower 5.1 User's Manual", Power Systems Engineering Research Center (Pserc), 2015.

[24] K. Paul and N. Kumar, "Application of MATPOWER for the Analysis of Congestion in Power System Network and Determination of Generator Sensitivity Factor", International Journal of Applied Engineering Research, ISSN 0973-4562 Volume 12, Number 6, pp.969-975, 2017.

[25] S. K. Sairy, "Impact the Nuclear Power Plant on Electrical Grid", Ph.D thesis, Faculty of Engineering, Al Azhar University, 2010. 